\title{
A workforce survey of dentists in Scotland
}

\author{
Dentists in general and community practice: a Scottish survey

\section{E. Russell and M. Leggate Br Dent J 2002; 193: 333-337}

\section{Objectives}

To identify the available workforce in general dental practice and to describe the job satisfaction, career and retirement plans of dentists in general and community practice.

\section{Design}

A postal cross-sectional survey.

\section{Setting}

Primary care dentists practising in Scotland in 2000.

\section{Materials and methods}

Semi-structured questionnaires were sent to all primary care dentists identified from the Scottish Dental Practice Division as being in practice in Scotland.

\section{Results}

The response rate was 70\% (1,335 GDPs and 187 CDPs). Although most dentists in both the GDS and CDS stated that they enjoyed their work, 35\% of GDPs would not now choose dentistry as a career. Eighty-three per cent of the GDPs' time was spent on clinical work, of which 5\% was not NHS-funded. Daily demotivation was reported by 70\%, most commonly citing the job itself and the NHS 'treadmill'. Two-thirds of CDPs were women, as were half of GDPs aged less than 30 . Only 35\% of CDPs planned early retirement but $80 \%$ of them felt underused. Two-thirds of GDPs planned to retire in their mid-50s, and a further quarter planned to work part-time. Of the former, only a quarter agreed that nothing would induce them to work beyond this time.

\section{Conclusion}

Conditions of work within primary care dentistry require modification to retain the current workforce and accommodate the increasing proportion of women. Part-time employment packages may encourage older practitioners to work for longer, and allow younger practitioners to fulfil family or personal commitments.

\section{IN BRIEF}

1 This paper is the first to present the actual NHS and independently funded working hours of dentists in general or community practice in Scotland in 2000, as reported by the respondents to a questionnaire survey.

1 The findings should allow manpower planners to focus on the reasons for loss of dentists and to consider ways of encouraging them to remain in dentistry for longer.

1 Comparisons of GDPs and CDPs provide beneficial insights for workforce and career planning.

1 This paper also complements the recent qualitative report of women dentists' concerns.

\section{COMMENT}

The planning of the dental workforce is a key area of concern not just in Scotland but throughout the UK. This paper provides some very necessary information to help fill in the many gaps in understanding the size and dynamics of the workforce. The paper complements other recent work undertaken by the Scottish Executive Health Department and NHS Education for Scotland. 1,2

The 'Toothousand Survey' 3 of all identifiable GDPs and CDPs in Scotland from which this paper is derived had two main aims: firstly, to describe the real available dental workforce and identify the potential loss from that workforce through planned career change, reduction in hours and early retirement. The second aim, which is the subject of another very worthwhile paper, ${ }^{4}$ was to explore the needs of dentists in Scotland for continuing professional development. This paper does an excellent job of presenting the survey results in a readable and understandable way.

The response rate to the postal survey at $70 \%$ was high and means that some conclusions can be drawn from the results. The real size of the GDP workforce, taking into account such factors as part time and non-NHS work is now clearer and expressed in terms of 'whole time equivalent' rather than a head count. Only 10 dentists were identified as being on a career break and planning to return to dentistry.

The potential loss to the workforce by the changing gender balance in GDS is highlighted, currently one third of GDPs are women but this rises to $51 \%$ of those under 30 years of age. Women GDPs who have had children take maternity leave and are more likely to work part-time thereafter. A further potentially larger loss is the stated aim of two thirds of GDPs to retire early, three-quarters reducing their hours before they go. CDPs were less likely to be planning early retirement or reduced hours.

Although a large proportion of all primary care dentists enjoyed their work, about 70\% felt demotivated on a daily basis with the NHS 'treadmill' being high on the list of reasons for GDPs and heavy workload and poor management for CDPs. The paper suggests a few innovative solutions to counteract this demotivation and maintain the current workforce.

This extensive survey provides much needed background information on the dental workforce and complements other recent work helping to make workforce planning a slightly less 'imprecise science'.

Robert Hamilton, Senior Dental Officer, Denburn Health Centre, Aberdeen

1. Scottish Executive Health Department. Workforce planning for dentistry in Scotland Astrategic review

2. SCPMDE. Characteristics and supply dynamics of the dental workforce in Scotland and projecting future supply

3. SCPMDE. A Scottish Survey of general and community dental practitioners 2000 , The Toothousand Project

4. Leggate M, Russell E. Attitudes and trends of primary care dentists to continuing professional development. BrDent JIn press. 